Voix et Images

voixetimages

\title{
Avant-propos : pour la continuité
}

\section{Jacques Allard}

Volume 1, numéro 1, septembre 1975

\section{Hubert Aquin}

URI : https://id.erudit.org/iderudit/013980ar

DOI : https://doi.org/10.7202/013980ar

Aller au sommaire du numéro

\section{Éditeur(s)}

Les Presses de l'Université du Québec

ISSN

0318-9201 (imprimé)

1705-933X (numérique)

Découvrir la revue

Citer ce document

Allard, J. (1975). Avant-propos : pour la continuité. Voix et Images, 1(1), 3-4. https://doi.org/10.7202/013980ar d'utilisation que vous pouvez consulter en ligne.

https://apropos.erudit.org/fr/usagers/politique-dutilisation/ 


\section{Avant-propos : pour la continuité}

Une nouvelle revue? Les fideles lecteurs de Voix et images du pays auront vite fait de s'y reconnaître. Derriere la nouveauté du format ( $p / u s$ économique), ils retrouveront vite l'essentiel de la collection qu'ils apprécient depuis 1967: l'objectif fondamental n'a pas changé qui consiste à publier des études consacrées exclusivement à la production québécoise.

La nouveauté se marque surtout en ceci: l'entrevue avec un écrivain (artiste, cinéaste ou autre producteur) reviendra dorénavant à chaque livraison; de même notre recension des publications utiles aux chercheurs du domaine québécois, et nos chroniques sur les dernieres parutions, le cinéma ou les autres domaines de l'activité culturelle. Ainsi, la revue ne fera que plus systématiquement ce que réalisait déjà la collection d'études.

On constatera aussi que le titre a été réduit aux deux premiers termes de l'ancienne triade: ils constituaient déjà l'appellation commode et familière de notre publication. Certains verront peut-être dans la disparition du troisième terme un signe des temps: la thématique du pays des années soixante a vécu. Nous croyons cependant qu'elle demeurera ici un champ d'études privilégié du discours national.

Voix et images continuera donc de véhiculer les recherches en cours, l'histoire littéraire fera bon ménage avec l'analyse idéologique, comme la critique avec la poétique et les sciences humaines. De plus, nous mettrons peu à peu l'accent sur l'analyse textuelle telle qu'elle peut être utilisée dans notre enseignement secondaire et collegial. Quant à ce qu'il est convenu d'appeler les textes de "création" (poèmes, nouvelles, etc.) nous accueillerons volontiers ceux qu'on voudra bien nous faire parvenir.

On remarquera enfin quelques changements à l'intérieur de l'équipe. Après avoir lancé la collection, c'est avec enthousiasme que j'ai accepté ma nouvelle responsabilité. Je veux d'ailleurs rendre hommage à la rédaction, à ses collaborateurs et à ses correspondants, tout en remerciant en particulier M. Renald Bérubé pour la constance et la qualité de son apport à la direction: qu'on en juge par la richesse et la diversité des textes parus dans le passé, en se reportant à l'index présenté à la fin de ce numéro. 
Publié maintenant sous l'égide du département des Études littéraires de l'Université du Québec à Montréal, Voix et images paraîtra trois fois l'an (en septembre, en décembre et en avril) et offrira à ses lecteurs la possibilité de s'abonner.

Ce n'est donc pas tout à fait une revue nouvelle que nous proposons à ceux qui s'intéressent au texte québécois. Et nous n'avons qu'un souhait: que cette inscription de la continuité dans la nouveauté permette à Voix et images d'être plus que jamais la revue des études québécoises.

Jacques Allard 